\title{
Microbial contamination in dental unit water lines (DUWL) in private dental clinics of Udaipur City, India
}

\author{
Santhosh Kumar, Arjun Singh , Disha Gupta, Goutham Balasubramanyam, Prabu D, Suhas Kulkarni \\ Department of Preventive and Community Dentistry
}

10.3396/ijic.V5i1.011.09

The present paper evaluated the microbial contamination of dental unit water lines (DUWL) in 50 dental clinics of Udaipur city, India. The presence of microbial contamination of water coming from dental units was first reported by Blake in $1963 .^{1}$ In the subsequent years since the discovery, research has been ongoing to identify potential bacterial human pathogens from dental unit waterlines (DUWL). The quality of dental unit water is of considerable importance since patients and dental staff are regularly exposed to water and aerosols generated from the dental unit.

This water hosts a diverse micro flora of bacteria, yeasts, fungi, viruses, protozoa, unicellular algae and nematodes. Once when it is present inside the dental unit, such microorganisms can settle on the inner tubing surface, initiating a chain of events that results in colonization, micro colony formation and, eventually, biofilm development becomes the primary reservoir for continued contamination of the system.

Some of the opportunistic pathogens identified in dental treatment water include Pseudomonas, Moraxella, Klebsiella, or other primary environmental organisms such as Legionella and Mycobacterium. ${ }^{2}$
American Dental Association (ADA) established a standard for waterlines as, not more than 200 colony forming units (CFU) per $\mathrm{mL}$ of aerobic heterotrophic bacteria for dental chair unit (DCU) output water. ${ }^{3}$ However, this standard has not been widely achieved, indicating the extent of this problem. However, the Center for Disease Control and Prevention (CDC) guidelines 2003 for infection control in dental health-care settings recommend that DCU output water should be less than $500 \mathrm{CFU} / \mathrm{mL}$ of aerobic heterotrophic bacteria. ${ }^{4}$

Microbial contamination of 50 randomly chosen dental clinics of Udaipur city with closed circuit water system was compared using tap water and distilled water. Tap and distilled water samples were collected and tested for Coliform and CFU (colony forming unit) count. The CFU count of the distilled water samples ranged from 0 to $3 \times 10^{2} \mathrm{CFU} / \mathrm{ml}$ and tap water samples $0.5 \times 10^{2}$ to $9.8 \times 10^{2}$. The mean CFU count per $\mathrm{ml}$ in tap water was 368.94 while in distilled water (36.76) it was well below the ADA and CDC specifications. Thus, it could be recommended to use distilled water as the source for dental unit waterlines.

\section{Corresponding author}

Dr Santhosh Kumar Tadakamadla, Department of Preventive and Community Dentistry,

Darshan Dental College and Hospital, Udaipur. India. 313001, Email: sanrescommunity@yahoo.com 
Since the origins of dental unit water contamination are now more clearly defined, substantial progress can be made by dental manufacturers and the scientific community in approaches to prevention and control. Due to the multiple ports of entry to the DUW system for microbes, no single method or device will completely eliminate the potential for cross infection. Combinations of currently available procedures and equipment, including anti-retraction devices, flushing, independent water supplies used in conjunction with biocide purges or fully autoclavable water line circuitry should provide water which is of a higher standard than that of drinking water. All these systems require strict adherence to maintenance protocols to perform to their full potential.

\section{References}

1. Blake GC. The incidence and control of bacterial infection of dental unit and ultrasonic scales. Br Dent J 1963; 15: 413-416.

2. Shearer BG. Biofilm and the dental office. / Am Dent Assoc 1996; 127: 181-189.

3. Anonymous. ADA statement on dental unit waterlines. / Am Dent Assoc 1996; 127: 185-186.

4. Kohn WG, Collins AS, Cleveland JL, et al. Centers for disease control and prevention $(C D C)$, guidelines for infection control in dental health-care settings-2003. MMWR Recommendations and Reports 2003; 52: 1-61. 